Article

\title{
Inelastic Supply of Fossil Energy and Competing Environmental Regulatory Policies
}

\author{
Sungwan Hong (iD) and Seung-Gyu Sim * \\ Graduate School of Economics, University of Tokyo, 7-3-1 Hongo, Bunkyo-ku, Tokyo 113-0033, Japan; \\ swhong@g.ecc.u-tokyo.ac.jp \\ * Correspondence: sgsim@e.u-tokyo.ac.jp
}

Received: 3 January 2018 ; Accepted: 20 January 2018 ; Published: 23 January 2018

\begin{abstract}
The inelastic supply of fossil energy in the international input market precipitates failure of Pigouvian taxation consequent to competition among governments, as imposition of an environmental tax increases (decreases) the marginal cost of domestic (foreign) firms. This paper demonstrates that unless the supply of fossil energy is perfectly elastic, cap-and-trade outperforms Pigouvian taxation in terms of the domestic welfare of adopting countries, and global welfare is maximized when all countries implement the alternative scheme. We further demonstrate that the linkage of permit markets, when the energy supply is sufficiently inelastic, improves global welfare.
\end{abstract}

Keywords: fossil energy supply; regulatory competition; cap-and-trade

JEL Classification: H23; L51; Q56; Q58

\section{Introduction}

Being aware of the (probably) most serious threat to the sustainability of human being and society, Global Warming and Climate Change, many scientists and policy makers make enormous efforts to find the reason of, and remedy for, the threat. All in all, they agree that the explosive increase in greenhouse gas emissions from the consumption of fossil energy that fueled the growth engine of the world economy over the past several centuries poses a serious threat to sustainable growth. (According to the U.S. Environmental Protection Agency, fossil fuel-related carbon dioxide $\left(\mathrm{CO}_{2}\right)$ emissions contributed approximately 65 percent of the greenhouse gas emissions worldwide in 2010 . In the United States, fossil energy combustion alone accounted for approximately 76 percent of total GWP-weighted emissions in 2014. The IPCC [1] attributes approximately 78 percent of the explosive increase in greenhouse gas emissions from 1970 to 2010 to fossil energy consumption.) The limited and inelastic supply of fossil energy, (Krichene [2] provides empirical evidence of the inelasticity of the supply of crude oil and natural gas.) coupled with each country's competitive eagernesss for economic growth, gives us an irrefutable warning that the threat cannot be resolved without international cooperative efforts.

After the largest greenhouse gas trading program, the European Union Emission Trading Scheme (EU ETS) was implemented as an important turning point in the history of the actual and effective international cooperation for environmental regulations, so called "cap-and-trade" schemes have been widely spread out. (A plot phase of EU ETS was implemented from 2005, the year Japan's Voluntary Emissions Trading Scheme (JVETS) was launched in 2008. The Korea Emission Trading Scheme (KETS) was begun in 2015. In addition, ten north-eastern states in the United States implemented the Regional Greenhouse Gas Initiative in 2015. The California Greenhouse Gas Solutions Act was signed into law in 2006, and adopted the cap-and-trade program to set the upper limit on statewide greenhouse gas emissions starting in 2010. To see more about EU ETS and US ETS, refer to Hintermann [3] and Stavins [4].) 
However, no theoretical studies of what enables emission trading schemes to outperform Pigouvian taxation without administrative failure have thus far been undertaken. This paper attempts to close the gap between "theory" and "reality" by showing the former to be superior to the latter in terms of domestic and global surplus in a globalized setting with international trade of inputs and outputs. It also examines under what conditions international linkage of tradable permit markets improves global welfare as well as the domestic welfare of participating countries.

In the wake of seminal work by Pigou [5], Pigouvian taxation was promulgated as a canonical approach to various environmental issues. The insightful theory implies that requiring polluting agents to internalize negative externalities enables the decentralized equilibrium to achieve the first best outcome. So-called Pigouvian taxation does not work properly, however, in the globalized situation in which an environmental policy of one government has heterogenous effects on domestic and foreign firms competing for inelastic supply of common input (e.g., fossil energy). In particular, we consider an international trade model in which both countries import fossil energy (input) and sell their final products (output) through the international market a la Cournot fashion. (Kiyono and Ishikawa [6] assumes a perfectly competitive final goods market to explain why developed countries adopt emission trading, whereas developing countries prefer direct taxation.)

Consuming fossil fuels during the production process inevitably generates pollutants (greenhouse gas), which creates environmental damage and lowers domestic consumer surplus. This market failure justifies government intervention, which can be implemented either using Pigouvian taxation or cap-and-trade schemes. Suppose that both governments adopt the former scheme. A unilateral environmental tax cut by one major country that implements Pigouvian taxation in its own territory increases its demand for fossil energy and consequently the fossil energy price. Thus, it raises the marginal costs of foreign firms and discourages production of the other countries. As a result, each government competitively lowers its environmental tax rate below the globally efficient level. Motivated by the failure of Pigouvian taxation, this paper develops a simple three-stage decision game between two symmetric non oil-producing countries to evaluate the relative performance of the alternative scheme, "cap-and-trade" together. (We borrow the basic structure of the game from Sim and Lin [7], who analyze a similar issue in the presence of cross border pollution.)

Each government chooses its environmental policy instrument, Pigouvian taxation or cap-and-trade, in the first stage, and, after observing the other's choice, adjusts the strength of regulation (the tax rate if it adopted the former, or cap if the latter) in the second stage. Inputs are purchased and outputs produced by the firms in each country in the third stage. Reflecting recent discussions of the linkage of permit markets, this paper also examines the welfare implications of the permit market linkage that allows free international trade of those permits, no matter where they were originally issued. (The discussions can be found in Helm [8], Copeland and Taylor [9], Carbone, Helm, and Rutherford [10], Flanchsland, Marschinski, and Edenhofer [11], Ranson and Stavins [12], and Doda and Taschini [13].)

In the decentralized setting in which only Pigouvian taxation is implemented, each government competitively lowers its environmental tax rate to increase the marginal cost of and discourage production by foreign firms. In the decentralized setting in which cap-and-trade as well as Pigouvian taxation may be implemented, adopting the former scheme and announcing the cap (domestic production) without knowing the other country's tax rate or cap preemptively neutralizes the adverse influence of the other country's raising the rivals' marginal cost strategy. It protects domestic production at the pre-committed level. Cap-and-trade outperforms Pigouvian taxation in terms of both global and domestic welfare because the associated "shield effect" expands each government's control over domestic production.

Whereas the strategy of "raising the rival's marginal cost," which Sartzetakis [14] mentioned, is competitively abused under the Pigouvian taxation, the aggressive effect of the strategy is simply nullified under the cap-and-trade scheme. However, neither of them reaches the first best outcome because the adverse influence exerted through the adjustment channel of the fossil energy price is not 
considered to lower domestic production for both countries as in the efficiency benchmark. As permit markets are linked such that permits are freely traded and used across borders, the marginal costs of all firms, regardless of location, respond to either country's environmental policy in the same direction. If one country issues more permits, all firms' marginal costs decline together. This synchronization leads each government to take into account foreign firms' marginal costs, even though the linkage elicits competition between government for greater revenue. When the energy supply is sufficiently inelastic, linking permit markets improve both domestic and global welfare.

After Weitzman [15], many studies have attempted to assess the relative advantages of Pigouvian taxation and emission trading in terms of "price control" versus "quantity control". However, most, assuming complete regulation that maintains all polluting agents within a target (or direct treatment) set, conclude that the schemes provide equivalent incentives to reduce emissions. A concise, insightful survey of the literature is provided by Goulder and Schein [16]. Relaxing the complete regulation assumption, Fowlie [17] and Baylis, Fullerton and Karney [18] examine the issue of "carbon leakage" consequent to incomplete regulation applied to only a subset of polluting agents. Assessing relative performance being an objective of neither study, however, both presume Pigouvian taxation and emission trading to work equivalently. In the study by Sim and Lin [7], the competitive dominance of the emission trading scheme is derived by the commitment on cross border pollution to the neighboring country, which can be made by the government adopting the emission trading scheme. (Similarly, Hoel [19] analyzes the transboundary pollution case with no explicit consideration of fossil fuel input. He concludes that each country choosing emission trading scheme holds as one of the Nash equilibria, while the present paper shows that it is a strictly dominant strategy unless the supply of fossil energy is perfectly elastic). The authors emphasize, on the basis of this setting, the significance of international cooperation and coordination in slowing down "global warming".

An extensive literature considering fossil fuel, e.g., Liski and Tahvonen [20], and Strand [21], focused on the optimal emission(or fossil fuel) taxation rule by analyzing non-cooperative Nash Equilibrium between importer and exporter, assuming that there is no unilateral deviation by one importing country. The present paper contributes to the literature by allowing unilateral deviation of an individual country and providing a detailed analysis of each (fossil fuel) importing country's strategy. It is because the latter scheme neutralizes the negative influence of raising the rival country's marginal cost strategy through the international price of fossil energy, which improves domestic welfare in a globalized setting.

The paper proceeds as follows. In Section 2, we introduce the theoretical framework, in Section 3, we perform efficiency analyses on each pair of environmental policies. The dominant strategy equilibrium is presented in Section 4, and the linkage issue is discussed in Section 5. Section 6 concludes the paper.

\section{The Model}

\subsection{Primitives}

We consider an economy that consists of two countries, country $A$ and country $B(i=A$ and $B)$. Each country has its own government that implements the environmental regulation and $m$ number of symmetric firms that consume fossil energy and emit pollutants in the production of homogenous products. In the first of the three stages, each government determines and publicly announces its environmental policy instrument, either Pigouvian taxation or cap-and-trade. In the second stage, a government that adopts Pigouvian taxation announces the per-unit tax rate $t_{i} \in \mathbb{R}_{+}$on domestic firms' emissions; a government that adopts cap-and-trade issues $n_{i}$ number of tradable permits, and (evenly) distributes $\bar{n}_{i j}$ permits to each domestic firm at unit price of $p_{i}^{0}$ via the Walrasian auction mechanism. The ex post market price of tradable permits in a cap-and-trade country $i \in\{A, B\}$ is denoted by $p_{i}$, which is determined through the market clearing condition of the domestic permit market. Production occurs in the third stage. In what follows, we proceed backwards. (Because we solve the subgame 
perfect equilibrium backwards, the results are robust even in the case where the government adopting the emission trading scheme is allowed to change the volume of tradable permits.)

\subsection{Firms}

All firms produce and sell homogenous goods à la Cournot fashion in a unique integrated market. (Yanase [22] and Kiyono and Ishikawa [6] analyzed an integrated output market, while both assumed the market to be perfectly competitive. Sim and Lin [7] also incorporated Cournot competitive international output market under the setting of cross-border pollution. Similarly, the case of imperfect competition was analyzed in various papers including Boom and Dijkstra [23] and Fowlie [17]. The former compared the efficiency of cap-based and rate-based emissions trading and the latter studied the leakage issue in the electricity market under the Cournot model.) Total demand for final goods, being evenly distributed in the two countries, is designated by $P: \mathbb{R}_{++} \rightarrow \mathbb{R}_{++}$, such that $P(\cdot)>0, P^{\prime}(\cdot)<0, P^{\prime \prime}(\cdot) \geq 0$, and $P^{\prime \prime}(Q) Q+P^{\prime}(Q)<0$. Firm $j \in\{1,2, \cdots, m\}$ in country $i \in\{A, B\}$ produces $q_{i j}$ units of final goods, consuming in the process $\kappa q_{i j}$ units of fossil energy. Denote by $q_{i}$ the total output of all firms in country $i \in\{A, B\}$, that is, $q_{i}=\sum_{j=1}^{m} q_{i j}$. Let $p_{e}$ be the unit price of fossil energy in the international input market. The inverse supply of fossil fuels is designated by $p_{e}=F\left(q_{A}+q_{B}\right)$, where $F: \mathbb{R}_{++} \rightarrow \mathbb{R}_{++}$is designated as $\lim _{Q \rightarrow 0} F(Q)=0, F^{\prime}>0$, and $F^{\prime \prime} \geq 0$. The price of fossil energy is convexly increasing, as the marginal cost of producing one unit of fossil energy increases convexly. As a special case, we investigate the potential outcome when the supply of fossil energy is perfectly elastic, such that $F(\cdot)>0$ and $F^{\prime}(\cdot)=0$. Firm $j \in\{1,2, \cdots, m\}$ in country $i \in\{A, B\}$ emits $e_{i j}$ units of carbon dioxide $\left(\mathrm{CO}_{2}\right)$. Emissions being proportional to each firm's consumption of fossil fuels (and, hence, output), $e_{i j}=\delta q_{i j}$. Parameter $\delta$ can be interpreted as carbon dioxide intensity. A firm that emits $e_{i j}$ units of pollutants should pay $t_{i} e_{i j}$ in a Pigouvian taxation country or purchase $p_{i} e_{i j}$ tradable permits in a cap-and-trade country. The aggregate level of emissions in country $i \in\{A, B\}$ is given by $e_{i}=\delta q_{i}$, which creates $D\left(e_{i}\right)$ units of disutility, where $D: \mathbb{R}_{++} \rightarrow \mathbb{R}_{++}$with $\lim _{e \rightarrow 0} D(e)=0, D^{\prime}(\cdot)>0$, and $D^{\prime \prime}(\cdot) \geq 0$.

Denote by $Q_{-i j}$ the total output of all firms other than firm $j \in\{1,2, \cdots, m\}$ in country $i \in\{A, B\}$. Taking the regulatory regimes and competing firms' strategies as given, firm $j \in\{1,2, \cdots, m\}$ in country $i \in\{A, B\}$ chooses $q_{i j} \in \mathbb{R}_{+}$such that

$$
q_{i j}=\underset{q \geq 0}{\operatorname{argmax}}\left[P\left(Q_{-i j}+q\right)-\kappa\left(Q_{-i j}+q\right) F\left(Q_{-i j}+q\right)-t_{i} \delta\right] q,
$$

in a Pigouvian taxation country, and

$$
q_{i j}=\underset{q \geq 0}{\operatorname{argmax}}\left[P\left(Q_{-i j}+q\right)-\kappa\left(Q_{-i j}+q\right) F\left(Q_{-i j}+q\right)\right] q-p_{i}\left(\delta q_{i j}-\bar{n}_{i j}\right)-p_{i}^{0} \bar{n}_{i j},
$$

in a cap-and-trade country. Under the cap-and-trade scheme implemented via the Walrasian auction mechanism, each firm is asked how many permits to purchase at every $p_{i} \in \mathbb{R}_{++}$, and the government determines $\left(n_{i}, \bar{n}_{i j}, p_{i}^{0}\right)$ such that $p_{i}^{0}=p_{i}$ and $\sum_{j=1}^{m}\left(\delta q_{i j}-\bar{n}_{i j}\right)=0$. The Walrasian auction mechanism treats each firm as a "price-taker" in the permit market and enables the governments to delegate emission pricing authority to the market mechanism without additional efficiency loss. (Note that partial or full free initial allowances can be incorporated in this mechanism, as long as such free allowances are considered a fixed transfer from the government to each firm without distorting firms' truthful revelations.)

Let $\tau_{i}=t_{i}$ if country $i \in\{A, B\}$ adopts the Pigouvian taxation scheme and $\tau_{i}=p_{i}$ if it adopts the cap-and-trade scheme. Each firm takes $\left(\tau_{A}, \tau_{B}\right)$ as given. Let $q_{i j}\left(\tau_{i}, \tau_{i^{\prime}}\right)$ and $q_{i}\left(\tau_{i}, \tau_{i^{\prime}}\right)$, respectively, be the quantity produced by firm $j \in\{1,2, \cdots, m\}$ in country $i \in\{A, B\}$ and the quantity produced by all firms in country $i \in\{A, B\}$ as the result of the mutual best responses. Then, $q_{i j}\left(\tau_{i}, \tau_{i^{\prime}}\right)$ should solve for 


$$
P^{\prime}\left(Q_{-i j}+q_{i j}\right) q_{i j}+P\left(Q_{-i j}+q_{i j}\right)=\kappa F\left(Q_{-i j}+q_{i j}\right)+\kappa q_{i j} F^{\prime}\left(Q_{-i j}+q_{i j}\right)+\tau_{i} \delta,
$$

where $q_{i j}=q_{i j}\left(\tau_{i}, \tau_{i^{\prime}}\right)$, and $Q_{-i j}=\sum_{j} q_{A j}\left(\tau_{A}, \tau_{B}\right)+\sum_{j} q_{B j}\left(\tau_{B}, \tau_{A}\right)-q_{i j}\left(\tau_{i}, \tau_{i^{\prime}}\right)$. The left-hand side of Equation (3) represents marginal revenue, the right-hand side, marginal cost. Note that the second order sufficient condition is globally satisfied as long as $P^{\prime}(Q)<0, P^{\prime \prime}(Q) Q+P^{\prime}(Q)<0, F^{\prime}(\cdot) \geq 0$, and $F^{\prime \prime}(\cdot) \geq 0$.

Lemma 1. Suppose that each government independently implements its own environmental regulation. An increase in the domestic emissions price reduces domestic and encourages foreign production. More specifically, given $\left(\tau_{A}, \tau_{B}\right)$,

$$
-\frac{\partial q_{i}\left(\tau_{i}, \tau_{i^{\prime}}\right)}{\partial \tau_{i}}>\frac{\partial q_{i^{\prime}}\left(\tau_{i^{\prime}}, \tau_{i}\right)}{\partial \tau_{i}}>0, \text { for each } i \in\{A, B\}
$$

Lemma 1 holds when each government independently implements its environmental policy. We will see in Section 5 that Lemma 1 does not hold when the permit markets are linked to each other. The detailed proofs of all lemmas are provided in Appendix A.

\subsection{Government}

Country $i^{\prime}$ s domestic surplus $\left(D S_{i}\right)$, which consists of consumer surplus, producer surplus, and government revenue, is rewritten as a function of $\left(q_{i}\left(\tau_{i}, \tau_{i^{\prime}}\right), q_{i^{\prime}}\left(\tau_{i^{\prime}}, \tau_{i}\right)\right)$ (or simply $\left.\left(\tau_{i}, \tau_{i^{\prime}}\right)\right)$. That is,

$$
D S_{i}\left(\tau_{i}, \tau_{i^{\prime}}\right)=\frac{1}{2} \int_{0}^{Q}\left[P\left(Q^{\prime}\right)-P(Q)\right] d Q^{\prime}+P(Q) q_{i}-F(Q) \kappa q_{i}-D\left(\delta q_{i}\right)
$$

where $Q=q_{A}+q_{B}$ and $q_{i}=q_{i}\left(\tau_{i}, \tau_{i^{\prime}}\right)$ for each $i \in\{A, B\}$. Suppose that country $i \in\{A, B\}$ adopts the Pigouvian taxation scheme. The government in country $i \in\{A, B\}$, by taking $\tau_{i^{\prime}} \in \mathbb{R}_{+}$as given, chooses $t_{i} \in \mathbb{R}_{+}$to maximize its domestic surplus in equation (5). For example, consider the subtree on which both governments commit to implementing Pigouvian taxation. We designate by superscript " $P P$ " the outcome on this subtree. Similarly, denote by " $C C$ " ( $C P$ ") the outcome on the subtree in which both countries (only country $A$ ) adopt(s) the cap-and-trade scheme. The optimal tax rate imposed by the government in country $i \in\{A, B\}$ is implicitly determined by

$$
\begin{gathered}
P^{\prime}\left(Q^{P P}\right)\left(\frac{q_{i}^{P P}-q_{i^{\prime}}^{P P}}{2}\right)+P\left(Q^{P P}\right)-\kappa F\left(Q^{P P}\right)-q_{i}^{P P} \kappa F^{\prime}\left(Q^{P P}\right)-\delta D^{\prime}\left(\delta q_{i}^{P P}\right) \\
+\left[P^{\prime}\left(Q^{P P}\right)\left(\frac{q_{i}^{P P}-q_{i^{\prime}}^{P P}}{2}\right)-q_{i}^{P P} \kappa F^{\prime}\left(Q^{P P}\right)\right] \frac{\partial q_{i^{\prime}}^{P P} / \partial t_{i}}{\partial q_{i}^{P P} / \partial t_{i}}=0,
\end{gathered}
$$

where $q_{i}^{P P}=q_{i}\left(t_{i}^{P P}, t_{i^{\prime}}^{P P}\right)$ and $Q^{P P}=q_{A}\left(t_{A}^{P P}, t_{B}^{P P}\right)+q_{B}\left(t_{B}^{P P}, t_{A}^{P P}\right)$.

Country $i \in\{A, B\}$, if it adopts the cap-and-trade scheme, determines the number of tradable permits and delegates emission pricing authority to the market mechanism. Remark that, throughout the paper, we confine our attention to the case in which the price of the tradable permits is strictly positive. (If the world demand for the final goods is sufficiently strong and/or the environmental damage from domestic pollution is negligible, the permit price can be negative.) The permit price is determined by the permit market clearing condition, which is given by

$$
\sum_{j=1}^{m} e_{i j}=\sum_{j=1}^{m} \delta q_{i j}\left(p_{i}, \tau_{i^{\prime}}\right)=n_{i}
$$

where $n_{i}$ is total number of permits initially issued and $\tau_{i^{\prime}}$ captures the rival country's environmental policy. Note that $\left(\partial p_{i}\right) /\left(\partial n_{i}\right)=\left[\delta\left(\partial q_{i}\right) /\left(\partial p_{i}\right)\right]^{-1}<0$, which implies that if the government issues more permits, permit price will drop. The government chooses $n_{i}$ to maximize its domestic surplus 
in Equation (5), subject to the market clearing condition of the domestic permit market in (7). If both countries implement cap-and-trade, each country's first order condition is given by

$$
P^{\prime}\left(Q^{C C}\right)\left(\frac{q_{i}^{C C}-q_{i^{\prime}}^{C C}}{2}\right)+P\left(Q^{C C}\right)-\kappa F\left(Q^{C C}\right)-q_{i}^{C C} \kappa F^{\prime}\left(Q^{C C}\right)-\delta D^{\prime}\left(\delta q_{i}^{C C}\right)=0
$$

for each $i \in\{A, B\}$, where $q_{A}^{C C}=q_{A}\left(p_{A}^{C C}, p_{B}^{C C}\right), q_{B}^{C C}=q_{B}\left(p_{B}^{C C}, p_{A}^{C C}\right)$, and $Q^{C C}=q_{A}^{C C}+q_{B}^{C C}$. Note that $\left(\partial q_{i^{\prime}}\right) /\left(\partial p_{i}\right)=0$ for each $i \in\{A, B\}$, domestic production in country $i \in\{A, B\}$ because it is controlled by the number of tradable permits, not being affected by the rival country's environmental regulation. Technically speaking, the second line in Equation (6) is dropped when the rival country adopts the cap-and-trade scheme. To see this, consider the subtree in which country $A$ implements the cap-and-trade, and country $B$ the Pigouvian taxation, scheme without loss of generality. Domestic production in country $A$, being determined by the permit allowance, is not affected by the environmental regulation of country $B$. This implies that $\left(\partial q_{A}\right) /\left(\partial t_{B}\right)=0$ in the production stage, which eliminates the second line in (6) and results in the same expression as in (8) for $i=B$. As a result, the first order condition of country $A$ is equivalent to (6) and that of country $B$ equivalent to (8).

For later use, denote as $A M C_{i}\left(q_{i}, q_{i^{\prime}}\right)$ the aggregate marginal cost perceived by the government in country $i \in\{A, B\}$, given $\left(q_{A}, q_{B}\right)$, and let $A M C\left(q_{A}, q_{B}\right)=A M C_{A}\left(q_{A}, q_{B}\right)+A M C_{B}\left(q_{B}, q_{A}\right)$, such that

$$
A M C\left(q_{A}, q_{B}\right)=\sum_{i=A, B} A M C_{i}\left(q_{i}, q_{i^{\prime}}\right)=\sum_{i=A, B}\left[\kappa F\left(q_{A}+q_{B}\right)+\kappa q_{i} F^{\prime}\left(q_{A}+q_{B}\right)+\delta D^{\prime}\left(\delta q_{i}\right)\right] .
$$

The first two terms in the square brackets of Equation (9) capture the sum of the marginal production cost of individual firms, the last term the sum of the marginal social damage to each country. $A M C\left(q_{A}, q_{B}\right)$ is thus interpreted as the sum of the aggregate marginal costs perceived by each government when each country concurrently increases domestic production by one unit. When both countries adopt the cap-and-trade scheme, $\left(q_{A}^{C C}, q_{B}^{C C}\right)$ should solve for

$$
2 P\left(q_{A}^{C C}+q_{B}^{C C}\right)=A M C\left(q_{A}^{C C}, q_{B}^{C C}\right)=\sum_{i=A, B} A M C_{i}\left(q_{i}^{C C}, q_{i^{\prime}}^{C C}\right) .
$$

Note that Equation (10) follows directly from (8).

\section{Efficiency Analysis}

We first settle the efficiency benchmark by denoting as $q_{A 1}^{*}=q_{A 2}^{*}=\cdots=q_{A m}^{*}=q_{B 1}^{*}=q_{B 2}^{*}=\cdots=q_{B m}^{*}$ the socially efficient allocation by the social planner, who maximizes the global surplus of the economy $\left(G S=D S_{A}+D S_{B}\right)$ by directing the quantity of final goods $\left(q_{A 1}^{*}, q_{A 2}^{*}, \cdots, q_{A m}^{*}, q_{B 1}^{*}, q_{B 2}^{*}, \cdots, q_{B m}^{*}\right)$ to individual firms in each country. The planner's decisions regarding output in country $i \in\{A, B\}$, and, in the entire global economy, are denoted by $q_{i}^{*} \in \mathbb{R}_{+}$and $Q^{*} \in \mathbb{R}_{+}$, respectively. The planner chooses $\left(q_{A}^{*}, q_{B}^{*}\right)$ to maximize

$$
\int_{0}^{q_{A}+q_{B}}\left[P\left(Q^{\prime}\right)-F\left(q_{A}+q_{B}\right) \kappa\right] d Q^{\prime}-D\left(\delta q_{A}\right)-D\left(\delta q_{B}\right) .
$$

Alternatively, consider the problem of the "constrained" planner who, taking (global) imperfect competition among firms as given, maximizes the global welfare by imposing taxes $\left(t_{A}, t_{B}\right)$. Rewriting (3) yields

$$
t_{i}^{*}=\frac{1}{\delta}\left[P^{\prime}\left(Q^{*}\right) q_{i}^{*}+m P\left(Q^{*}\right)-m \kappa F\left(Q^{*}\right)-\kappa q_{i}^{*} F^{\prime}\left(Q^{*}\right)\right], \text { for each } i \in\{A, B\} .
$$

Plugging the first best allocation $\left(q_{A}^{*}, q_{B}^{*}\right)$ by the unconstrained planner into (12) yields $\left(t_{A}^{*}, t_{B}^{*}\right)$, which implies that the constrained planner can implement the first best outcome by imposing $\left(t_{A}^{*}, t_{B}^{*}\right)$. In other words, the potential efficiency loss from international imperfect competition can be controlled 
by allowing the constrained planner two policy tools, $\left(t_{A}^{*}, t_{B}^{*}\right)$. To implement the cap-and-trade scheme in country $i \in\{A, B\}$, the constrained planner can issue $n_{i}^{*}$ number of permits, such that $p_{i}^{*}=t_{i}^{*}$ solves the market clearing condition in (7), given $\left(q_{A}^{*}, q_{B}^{*}\right)$. Lemma 2 concludes that decentralizing the production decision and introducing Cournot competition among individual firms causes no efficiency loss, whether the constrained planner implements "price control" or "quantity control."

Lemma 2. There exists a unique solution of $\left(q_{A}^{*}, q_{B}^{*}\right)$ in the unconstrained planner's problem. The constrained planner can also achieve the first best allocation of $\left(q_{A}^{*}, q_{B}^{*}\right)$, whether price control or quantity control is implemented.

The unconstrained as well as constrained planner implements the pair, $\left(q_{A}^{*}, q_{B}^{*}\right)$, such that

$$
2 P\left(q_{A}^{*}+q_{B}^{*}\right)=A M C\left(q_{A}^{*}, q_{B}^{*}\right)+\sum_{i=A, B} \kappa q_{i}^{*} F^{\prime}\left(q_{A}^{*}+q_{B}^{*}\right) .
$$

In Equation (13), the left-hand side captures the sum, in each country, of the marginal consumer's willingness to pay. The right-hand side captures both countries' marginal social costs, marginal production cost, and environmental damage. The last term captures an increase in foreign firms' cost consequent to one country's increase in domestic production, and input price, which typically cannot be considered in a decentralized equilibrium. (An exception, described later, is the case in which permit markets are linked internationally.) Note that $F^{\prime}(\cdot)>0$, which renders the right-hand side of (13) greater than that of (10) for any $\left(q_{A}, q_{B}\right) \in \mathbb{R}_{+} \times \mathbb{R}_{+}$. The left-hand side of (13) being strictly decreasing in $\left(q_{A}+q_{B}\right)$, the right-hand side is strictly increasing and the optimal allocation of $\left(q_{A}^{*}, q_{B}^{*}\right)$ well defined.

We now decentralize the second stage decision by each government. When both countries implement Pigouvian taxation, total output $\left(q_{A}^{P P}, q_{B}^{P P}\right)$ should solve for

$$
2 P\left(q_{A}^{P P}+q_{B}^{P P}\right)=A M C\left(q_{A}^{P P}, q_{B}^{P P}\right)+\sum_{i=A, B} \kappa q_{i}^{P P} F^{\prime}\left(q_{A}^{P P}+q_{B}^{P P}\right)\left(\frac{\partial q_{i^{\prime}} / \partial t_{i}}{\partial q_{i} / \partial t_{i}}\right) .
$$

When country $A$ implements cap-and-trade and country $B$ Pigouvian taxation, total output $\left(q_{A}^{C P}, q_{B}^{C P}\right)$ should solve for

$$
\begin{aligned}
2 P\left(q_{A}^{C P}+q_{B}^{C P}\right)= & A M C\left(q_{A}^{C P}, q_{B}^{C P}\right) \\
& -\left[P^{\prime}\left(Q^{C P}\right)\left(\frac{q_{A}^{C P}-q_{B}^{C P}}{2}\right)-\kappa q_{A}^{C P} F^{\prime}\left(Q^{C P}\right)\right] \frac{\partial q_{B} / \partial p_{A}}{\partial q_{A} / \partial p_{A}}
\end{aligned}
$$

In Equations (10) and (13)-(15), the left-hand sides are the same and strictly decreasing in $\left(q_{A}+q_{B}\right)$, the right-hand sides different and strictly increasing in $\left(q_{A}+q_{B}\right)$. (Without loss of generality, we can obtain $q_{A}=q_{B}=\left(q_{A}+q_{B}\right) / 2$ by restricting attention to the symmetric solution. We can then, with a small abuse of notation, define $A M C_{i}\left(q_{A}+q_{B}\right)$ instead of $A M C_{i}\left(q_{i}, q_{i^{\prime}}\right)$.) The intersection points can be ordered thus: $P\left(q_{A}^{*}+q_{B}^{*}\right) \geq P\left(q_{A}^{C C}+q_{B}^{C C}\right) \geq \max \left\{P\left(q_{A}^{P P}+q_{B}^{P P}\right), P\left(q_{A}^{C P}+q_{B}^{C P}\right), P\left(q_{A}^{P C}+q_{B}^{P C}\right)\right\}$. The equality holds only when $F^{\prime}(\cdot)=0$. Figure 1 , by restricting attention to the symmetric solution, such that $q_{A}=q_{B}=\left(q_{A}+q_{B}\right) / 2$, summarizes the output price, quantity, and global welfare for each case. (The second order sufficient condition globally holds, which implies that there exists a unique optimum. It also predicts that "the closer (to the optimum point), the better welfare".) The second order sufficient condition of the social planner being globally satisfied, the following welfare implication is obtained.

Lemma 3. Unless the supply of fossil energy is perfectly elastic $\left(F^{\prime}(\cdot)>0\right)$,

$$
G S^{*}>G S^{C C}>\max \left\{G S^{P P}, G S^{C P}, G S^{P C}\right\} .
$$


In the special case with perfectly elastic supply of fossil energy $\left(F^{\prime}(\cdot)=0\right)$,

$$
G S^{*}=G S^{C C}=G S^{P P}=G S^{C P}=G S^{P C} .
$$

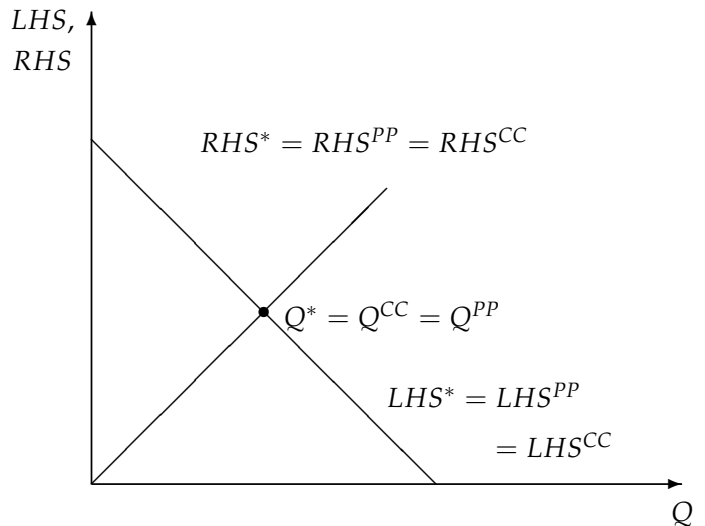

(a)

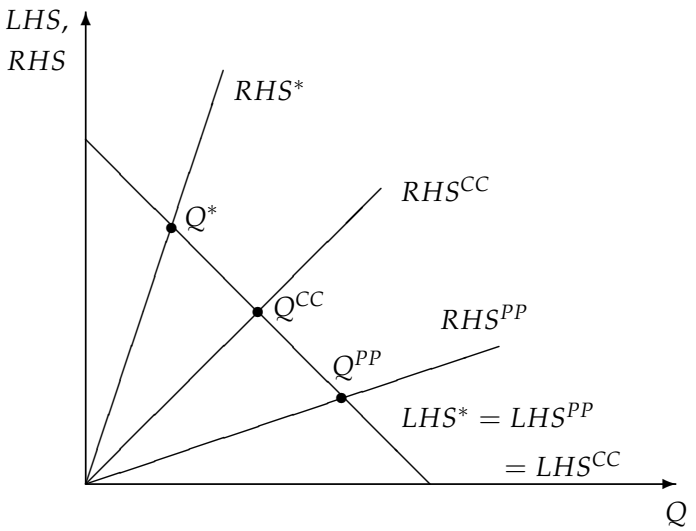

(b)

Figure 1. Efficiency Analysis. (a) with perfectly elastic supply of fossil energy; (b) with inelastic supply of fossil energy. Figure 1 depicts the left- and right-hand sides of Equations (10), (13), and (14) by restricting attention to the symmetric solution of each equation. (a) shows that when the supply of fossil energy is perfectly elastic, $q_{A}^{*}+q_{B}^{*}=q_{A}^{C C}+q_{B}^{C C}=q_{A}^{P P}+q_{B}^{P P} ;(\mathbf{b})$ shows that when the supply of fossil energy is inelastic, $q_{A}^{*}+q_{B}^{*}<q_{A}^{C C}+q_{B}^{C C}<q_{A}^{P P}+q_{B}^{P P}$ so that $G S\left(q_{A}^{*}, q_{B}^{*}\right)>G S\left(q_{A}^{C C}, q_{B}^{C C}\right)>$ $G S\left(q_{A}^{P P}, q_{B}^{P P}\right)$.

\section{Decentralized Equilibrium}

We show in this section that adopting the cap-and-trade scheme in the first stage is the strict dominant strategy for each country. We do so by examining which policy instrument accrues greater domestic surplus to one country when the other country adopts Pigouvian taxation first and the cap-and-trade scheme later. We focus in this section on the nontrivial case with $F^{\prime}(\cdot)>0$. (One can readily infer that if $F^{\prime}(\cdot)=0$, both policy instruments yield the same outcome.)

Without loss of generality, suppose that country $B$ adopts the Pigouvian taxation scheme. If country $A$ adopts Pigouvian taxation as well, both countries competitively lower their tax rates. That a decrease in one country's tax rate, by increasing the input price (Sartzetakis [14] analyzes the welfare implication of "raising rivals' cost strategies" in the permit market of an autarky economy. Dertwinkel-Kalt, Haucap, and Wey [24] recently applied "raising rivals' cost strategies" to the input price discrimination issue in an autarky setting), encourages domestic production and discourages foreign production, leading each government to maintain its tax rate at an inefficiently low level.

Country $A$, if it adopts instead the cap-and-trade scheme, nullifies the negative influence from the foreign environmental policy and protects the domestic production through direct "quantity control." Country $B$ optimally adjusts its tax rate by putting more weights on domestic environmental damage. The cap-and-trade scheme gives an effective "shield" to the adopting country, which discourages the other country's aggressive policy. Lemma 4 shows the cap-and-trade scheme by country $A$ to accrue a larger domestic surplus to the adopting country than to the other country adopting Pigouvian taxation, and to perform better than the Pigouvian taxation scheme, although whether $G S^{C P}>G S^{P P}$ remains ambiguous. 
Lemma 4. Suppose, without loss of generality, that country B implements the Pigouvian taxation scheme. When country A adopts the cap-and-trade scheme,

$$
q_{A}\left(p_{A}^{C P}, t_{B}^{C P}\right)>q_{B}\left(t_{B}^{C P}, p_{A}^{C P}\right) \text { and } p_{A}^{C P}<t_{B}^{C P} .
$$

Greater domestic surplus accrues to country A when it adopts cap-and-trade than when it adopts Pigouvian taxation $\left(D S_{A}^{C P}>D S_{A}^{P P}\right)$.

Suppose that country $B$ adopts the cap-and-trade scheme. It makes a commitment on the amounts of input to purchase and output to produce. The government in country $A$ realizes that its raising the rival's marginal cost strategy does not work and that its adoption of the cap-and-trade scheme induces country $B$ to strengthen its environmental regulation in response to the same consideration. The "shield effect" of cap-and-trade scheme, by nullifying the raising rival's marginal cost strategy of the opponent, encourages the opponent government to put more weights on its environmental damages and raise their emission price. Lemma 5 shows that, when country $B$ adopts the cap-and-trade scheme, country $A$ can expand its domestic surplus by implementing the cap-and-trade rather than the Pigouvian taxation scheme.

Lemma 5. Suppose, without loss of generality, that country B implements the cap-and-trade scheme. When country A implements the cap-and-trade scheme as well, a unique symmetric outcome is obtained, and country A's surplus is greater when it chooses the cap-and-trade over the Pigouvian taxation scheme $\left(D S_{A}^{P C}<D S_{A}^{C C}\right)$.

Lemmas 4 and 5 jointly imply that adopting the cap-and-trade scheme is the strict dominant strategy of each country, and, together with Lemma 3, imply that global surplus is maximized when both countries adopt the cap-and-trade scheme. In particular, Lemma 5 proves the existence and uniqueness of the decentralized equilibrium. Proposition 1 summarizes this result.

Proposition 1. Unless the supply of fossil fuels is perfectly elastic, it is the strictly dominant strategy for each country to implement the cap-and-trade scheme. Global surplus is maximized when all countries choose their own strict dominant strategy.

Proof. This is straightforward from Lemmas 3-5.

Although the cap-and-trade scheme has been widely adopted, many countries still rely on Pigouvian taxation. The novel point of Lemma 3 and Proposition 1 is that global surplus can improve without technological innovation. (One aspect we leave to future research is to extend our model to a dynamic setting with technological innovation. See Biglaiser, Horowitz, and Quiggin [25], Fischer [26], Weber and Neuhoff [27], Kim and Lee [28], D'Amato and Dijkstra [29], and Sim and Hong [30] for various issues regarding technological innovation.) This point raises one more relevant question, "whether the market equilibrium can achieve the first best outcome". It is discussed in the following section.

\section{Permit Market Linkage}

\subsection{The Basic Framework}

Thus far, we have shown that, when both countries implement the cap-and-trade scheme, global welfare is maximized, but remains below the first best level. We investigate here whether linking the domestic permit markets further improves global, as well as each country's domestic, welfare. "Linking their permit markets" means that each country $i \in\{A, B\}$ independently determines its domestic permit allowances $n_{i}$, but issued permits can be traded and used even in the other country. This can be understood as a form of "weak coalition" sharing the same permit price. (Each 
country shares the common emission price, but maintains its regulatory power, at least partially. It is different from the permit market unification examined by Sim and Lin [7], in which an upper authority other than each local government issues internationally tradable permits.) Instances of this widely implemented "direct linkage" include, for example, California with Quebec and EU ETS with other European countries. (See Ranson and Stavins [12] for summary lists of linked countries.)

We link the two permit markets in our model, (Due to the symmetry, the market distortion identified by Helm [8] does not exist in our model. Our model also differs from Doda and Taschini [13], which assumes that the total permit allowances are the same under both non-linked case and linked case, while governments endogenously set the allowances in our model) and denote by the superscript $L$ the outcome obtained by the linkage. When the permit markets are linked, the government in country $i \in\{A, B\}$ determines $n_{i}$ to maximize

$$
D S_{i}=\frac{1}{2} \int_{0}^{Q}\left[P\left(Q^{\prime}\right)-P(Q)\right] d Q^{\prime}+[P(Q)-F(Q) \kappa-p \delta] q_{i}+p n_{i}-D\left(\delta q_{i}\right),
$$

where $Q=q_{A}+q_{B}$ and $p=p\left(n_{A}, n_{B}\right)$. Note that, compared to Equation (5), Equation (19) has two additional terms associated with government revenue, $\left(-p \delta q_{i}+p n_{i}\right)$. It is not necessarily true that $n_{i}=\delta q_{i}$ for any $i \in\{A, B\}$.

The market clearing condition in the linked permit markets implicitly determines $p\left(n_{A}, n_{B}\right)$ such that

$$
\sum_{i=A, B} \sum_{j=1}^{m} e_{i j}=\sum_{i=A, B} \sum_{j=1}^{m} \delta q_{i j}\left(p\left(n_{A}, n_{B}\right)\right)=n^{L},
$$

where $n^{L}=n_{A}+n_{B}$. Each country maximizes its domestic welfare by controlling domestic permit allowances. Note that a unilateral increase in country $i^{\prime}$ s permit allowance reduces the permit price universally, which affects all firms in the same manner, that is, $\frac{\partial q_{i}(n)}{\partial p} \frac{\partial p}{\partial n(i)}>0$ and $\frac{\partial q_{i^{\prime}}(n)}{\partial p} \frac{\partial p}{\partial n(i)}>$ 0 for each $i \in\{A, B\}$. For each country, the first order condition with respect to $n_{i}$ is given by

$$
\begin{gathered}
P^{\prime}\left(Q^{L}\right)\left(\frac{q_{i}^{L}-q_{i^{\prime}}^{L}}{2}\right)+P\left(Q^{L}\right)-q_{i} \kappa F^{\prime}\left(Q^{L}\right)-\kappa F\left(Q^{L}\right)-p^{L} \delta-\delta D^{\prime}\left(\delta q_{i}\right) \\
+\left[P^{\prime}\left(Q^{L}\right)\left(\frac{q_{i}^{L}-q_{i^{\prime}}^{L}}{2}\right)-q_{i} \kappa F^{\prime}\left(Q^{L}\right)\right] \frac{\partial q_{i^{\prime}} / \partial p}{\partial q_{i} / \partial p}+\frac{n_{i}^{L}-\delta q_{i}^{L}}{\partial q_{i} / \partial p}+p^{L}\left[\frac{\partial q_{i}}{\partial p} \frac{\partial p}{\partial n_{i}}\right]^{-1}=0,
\end{gathered}
$$

for each $i \in\{A, B\}$. For any symmetric equilibrium, $n_{A}^{L}=n_{B}^{L}=\delta q_{A}^{L}=\delta q_{B}^{L}$ and $\left(\partial q_{A}\right) /(\partial p)=$ $\left(\partial q_{B}\right) /(\partial p)<0$. Summing Equation (21) for each $i \in\{A, B\}$, and reordering, yields the equilibrium condition:

$$
2 P\left(q_{A}^{L}+q_{B}^{L}\right)=A M C\left(q_{A}^{L}, q_{B}^{L}\right)+\sum_{i=A, B} \kappa q_{i}^{L} F^{\prime}\left(q_{A}^{L}+q_{B}^{L}\right)-\left(\frac{1}{\delta}-2 \delta\right) p\left(q_{A}^{L}, q_{B}^{L}\right)
$$

The second and last terms on the right-hand side of Equation (22) identify the sources of efficiency gain and loss from the linkage. The presence of the second term, $\sum_{i=A, B} \kappa q_{i}^{L} F^{\prime}\left(q_{A}^{L}+q_{B}^{L}\right)$, shows global welfare to have improved in the linkage relative to the non-linkage case. As mentioned above, governments in the decentralized equilibrium that allow the non-linked cap-and-trade scheme do not take into account the increase in foreign firms' marginal cost through the adjustment process associated with fossil energy, which is the source of the efficiency loss. Linking the permit markets synchronizes the response of all firms' marginal cost, which is consequently taken into account by both governments that, as a result, maintain domestic production at the first best level. 
The decentralized determination of the number of tradable permits results in another efficiency loss; however, this one is due to competition between two governments seeking higher revenue from selling the permits. The last term in Equation (22), originating from $\left(-p \delta q_{i}+p n_{i}\right)$ in (19), captures the efficiency loss associated with governments' competition for revenue. The efficiency loss disappears when carbon dioxide intensity is fixed at $\sqrt{1 / 2}$, that is, $\delta=\sqrt{1 / 2}$, at which point the marginal revenue of each of the "two" governments is offset by the marginal payment of its domestic firms. By chance, the first best outcome can be achieved. In general, if $\delta>(<) \sqrt{1 / 2}$, the value of last term in (22) is positive (negative), so each government competitively issues fewer (more) permits. The competitive pressure for government revenue is mitigated (aggravated) with carbon dioxide intensity (i.e., demand for permits). Whereas the welfare implication of the combined effect of "synchronization of firms' marginal costs" and "competition for government revenue" is ambiguous, the following proposition presents a clear welfare implication of the elasticity of the energy supply.

Proposition 2. Suppose that two countries agree to admit the permits issued by each other's governments. If the supply of fossil energy is sufficiently elastic, linking the permit markets negatively affects the global and domestic welfare of both countries. If the supply of fossil energy is sufficiently inelastic, however, the linkage case yields higher global and domestic welfare than the non-linkage case.

Proof. Consider the case which the supply of fossil energy is sufficiently elastic such that $\sum_{i=A, B} \kappa q_{i}^{L} F^{\prime}\left(q_{A}^{L}+q_{B}^{L}\right)-\left(\frac{1}{\delta}-2 \delta\right) p\left(q_{A}^{L}, q_{B}^{L}\right)<0$ in (22). Then, a comparison of (10) and (22) implies $2 P\left(q_{A}^{L}+q_{B}^{L}\right)<2 P\left(q_{A}^{C C}+q_{B}^{C C}\right)$, so that $G S^{L}<G S^{C C}$. Since each country equally divides global surplus, $D S_{A}^{L}=D S_{B}^{L}<D S_{A}^{C C}=D S_{B}^{C C}$. Similarly, if the supply of fossil energy is sufficiently inelastic such that $\sum_{i=A, B} \kappa q_{i}^{L} F^{\prime}\left(q_{A}^{L}+q_{B}^{L}\right)-\left(\frac{1}{\delta}-2 \delta\right) p\left(q_{A}^{L}, q_{B}^{L}\right) \geq 0$, it immediately follows that $G S^{L} \geq G S^{C C}$ and $D S_{A}^{L}=D S_{B}^{L} \geq D S_{A}^{C C}=D S_{B}^{C C}$.

Proposition 2 is derived from the fact that the relative sizes of the second and third terms on the right-hand side of Equation (22) determine the sign of the efficiency gain from linking the permit markets. If the energy supply is perfectly elastic $F^{\prime}(\cdot)=0$, the second term becomes zero. If sufficiently inelastic, it becomes larger than the (absolute value of the) third term such that linking the permit markets improves global welfare regardless of carbon dioxide intensity $\delta$. Proposition 2 presents a generalized result of Holtsmark and Sommervoll [31], who argue that linkage increases emissions and, hence, reduces efficiency. Their result can be understood as a special case without interdependency in the cost structure (or the case with perfectly elastic supply of fossil energy).

\subsection{Illustrative Examples}

Consider a simple setting with

$$
P\left(q_{A}+q_{B}\right)=100-\left(q_{A}+q_{B}\right), \kappa=1, D\left(e_{i}\right)=\left(\delta q_{i}\right)^{3}, \text { and } F(Q)=\frac{1}{10} Q^{\eta} .
$$

If the environmental damage function is not sufficiently convex, a subsidy for each domestic firm rather than a tax can be optimal. In order to avoid this situation, we posit a cubic function for $D(\cdot)$. By construction, $\eta$ is the inverse of the energy supply's elasticity. The perfectly elastic supply being characterized by $\eta=0$, as $\eta$ becomes larger, the supply becomes inelastic. The simulation results are presented in Figure 2 with $\eta \in[0,5]$ and $\delta \in\{0.5, \sqrt{1 / 2}, 1.0\}$.

The three panels on the top (bottom) row of Figure 2 show the aggregate output (global welfare) ratios of the decentralized equilibrium outcome to the first best outcome. In each panel, $\eta$ is plotted on the horizontal and the ratio on the vertical axis, with $\delta \in\{0.5, \sqrt{1 / 2}, 1.0\}$. The blue solid (red dashed) line in each panel represents the ratios of the non-linked (linked) equilibrium outcome to the first best outcome. The flat solid in the middle indicates 100 percent, the efficiency benchmark. 


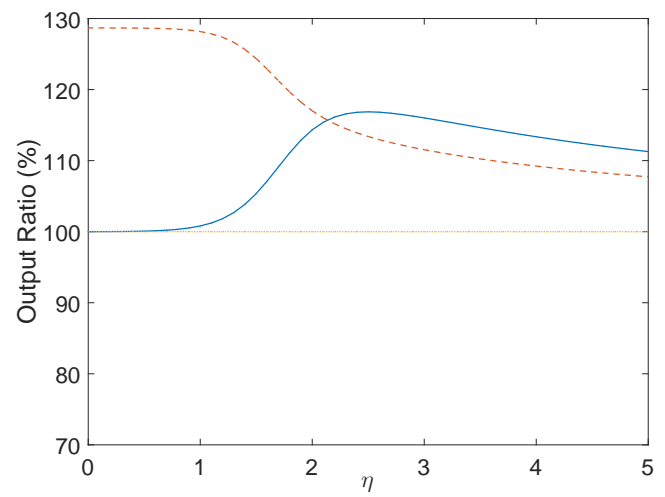

(a)

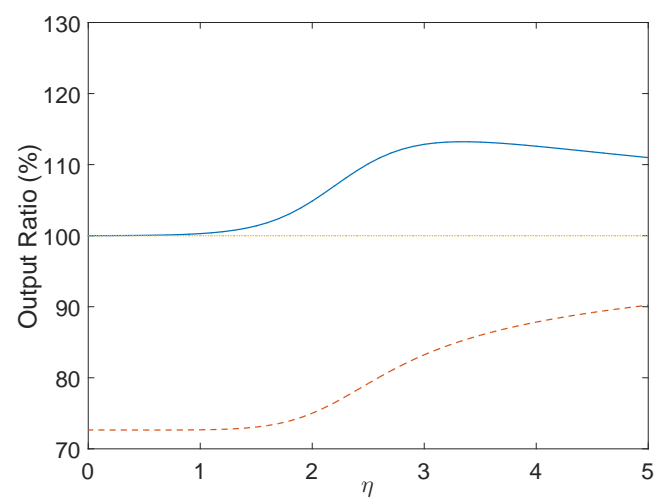

(c)

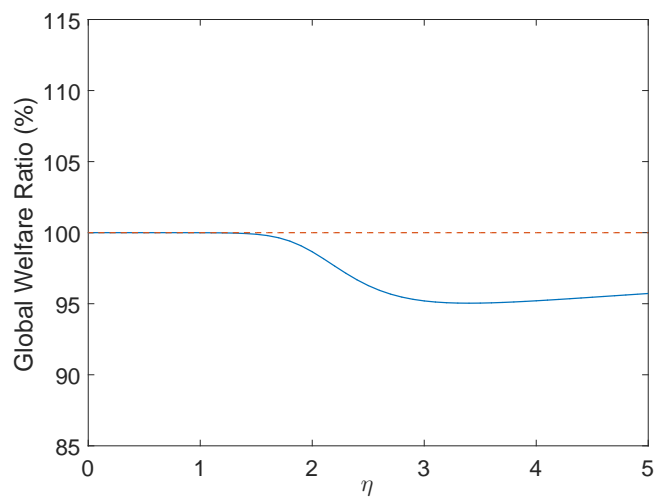

(e)

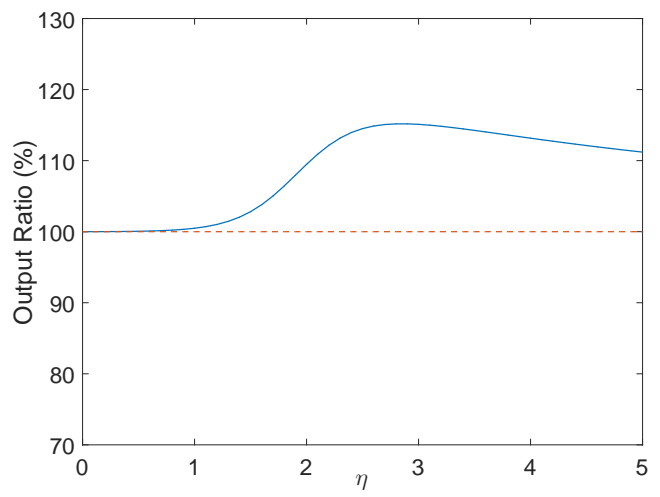

(b)

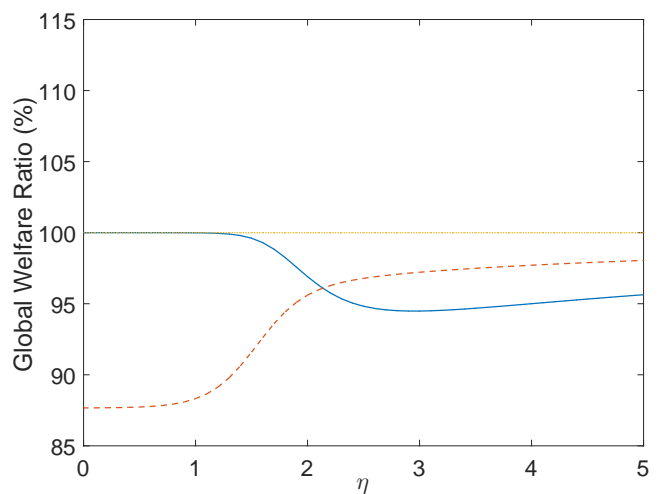

(d)

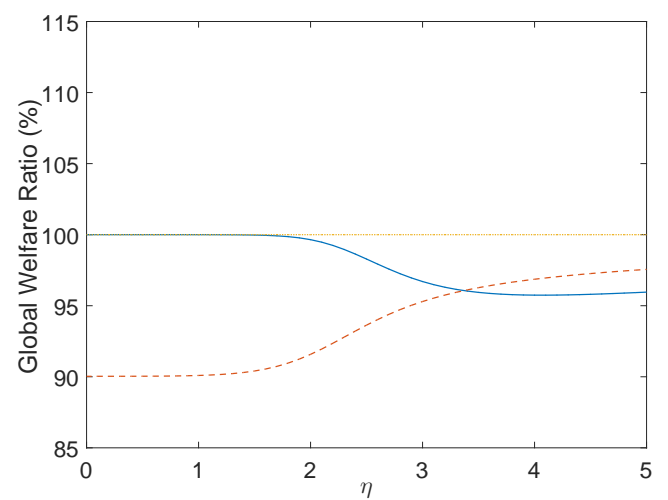

$(\mathbf{f})$

Figure 2. Linkage Outcome vs. Non-linkage Outcome. Figure 2 plots the loci of aggregate output and global welfare ratios of the decentralized outcome to the first best outcome in the top and bottom rows, respectively. (a) with $\delta=0.5$ and (d) with $\delta=0.5$; (b) with $\delta=\sqrt{1 / 2}$ and (e) with $\delta=\sqrt{1 / 2}$; and (c) with $\delta=1.0$ and (f) with $\delta=1.0$, respectively, represent the case with $\delta=0.5, \sqrt{1 / 2}$, and 1.0. In each panel, $\eta$ (the outcome ratio) appears on the horizontal (vertical) axis. The blue solid (red dashed) lines in each panel represent the aggregate output ratios of the decentralized outcome without (with) the linkage to the first best outcome with respect to $\eta \in[0,5]$. By construction, the flat line in the middle represents the efficiency benchmark.

Looking first at the blue solid line, the ratios of the non-linked equilibrium outcome to the efficiency benchmark, we can see that no output ratios are below and no welfare ratios above the flat 
efficiency benchmark line in any panel. As expected, when $\eta=0$, the first best outcome is achieved regardless of $\delta$. However, as the energy supply becomes inelastic, it produces more than the first best outcome, which results in efficiency loss. The red dashed lines are affected by $\delta$. When $\delta<\sqrt{1 / 2}$, the red dashed line in panel (a) indicates "over-production", when $\delta>\sqrt{1 / 2}$, the red dashed line in panel (c) "underproduction", compared to the first best outcome. When $\delta=\sqrt{1 / 2}$, it is at the efficiency benchmark line in panel (b). When $\delta \neq \sqrt{1 / 2}$, the loci of all welfare ratios remain below the efficiency benchmark line regardless of $\delta$. Note that the red dashed line crosses the blue solid line once from below. Suppose that each government is allowed to choose one policy instrument, Pigouvian taxation, cap-and-trade without proposing the linkage, or cap-and-trade with proposing the linkage. The crossing of the lines implies that, when $\eta$ is large (small), to choose cap-and-trade with (without) proposing the linkage, being the mutual dominant strategy, maximizes global welfare.

\section{Conclusions}

Motivated by the substantial volume of greenhouse gases emitted in the burning of fossil fuels, this paper analyzes the performance of the Pigouvian taxation and cap-and-trade environmental regulation instruments in a globalized setting in which firms in each country purchase fossil energies from an international input market and sell final goods in an integrated output market. We show that, unless the supply of fossil energies is perfectly elastic, the cap-and-trade scheme strictly outperforms the Pigouvian taxation scheme, and that global surplus is maximized when all countries implement the former. We further show that, if the energy supply is sufficiently inelastic, linking permit markets improves both domestic and global welfare.

It cannot be overemphasized that the greenhouse gas problem would be mitigated and solved only through international cooperation and coordination. In particular, encouraging widespread adoption of the cap-and-trade scheme and linking permit markets could be a meaningful step towards inducing such international cooperation. To convince policy makers and practitioners in each country, empirical evidence that the adoption of an emission trading scheme is a strictly dominant strategy for each country is useful and somewhat required. We leave it for future empirical research to determine whether our simplification strategy in the theoretical model has led us to overvalue the cap-and-trade scheme.

Acknowledgments: We have benefited from discussions with Sung Jin Kang and Soohyun Oh and their helpful comments. Seung-Gyu Sim appreciates of the hospitality of Department of Economics, University of Wisconsin-Madison, a substantial part of this research having been done during his stay in Madison.

Author Contributions: Seung-Gyu Sim and Sungwan Hong together designed the model, analyzed the simulation results, and wrote the paper.

Conflicts of Interest: The authors declare no conflict of interest.

\section{Appendix A. Mathematical Appendix}

Proof of Theorem 1. Summing Equation (3) for all $j \in\{1,2, \cdots, m\}$ in each country yields

$$
P^{\prime}(Q) q_{i}+m P(Q)-\kappa m F(Q)-\kappa q_{i} F^{\prime}(Q)-m \tau_{i} \delta=0,
$$

for each $i \in\{A, B\}$. As before, $Q=q_{A}\left(\tau_{A}, \tau_{B}\right)+q_{B}\left(\tau_{B}, \tau_{A}\right)=\sum_{j=1}^{m} q_{A j}\left(\tau_{A}, \tau_{B}\right)+\sum_{j=1}^{m} q_{B j}\left(\tau_{B}, \tau_{A}\right)$. Summing up Equation (A1) for each $i \in\{A, B\}$ yields

$$
P^{\prime}(Q) Q+2 m P(Q)-2 \kappa m F(Q)-\kappa Q F^{\prime}(Q)=m\left(\tau_{A}+\tau_{B}\right) \delta .
$$

Note the left-hand side of Equation (A2) strictly declines with $Q$. If either $\tau_{A}$ or $\tau_{B}$ increases unilaterally, the right-hand side of (A2) increases. Thus, we infer that

$$
\frac{\partial\left(q_{A}\left(\tau_{A}, \tau_{B}\right)+q_{B}\left(\tau_{B}, \tau_{A}\right)\right)}{\partial \tau_{i}}<0 \text { for each } i \in\{A, B\}
$$


Now, we want to show that $\left(\partial q_{i^{\prime}}\right) /\left(\partial \tau_{i}\right)>0$ for each $i, i^{\prime} \in\{A, B\}$ and $i \neq i^{\prime}$. First, suppose on the contrary that $\left(\partial q_{B}\right) /\left(\partial \tau_{A}\right) \leq 0$. An increase in $\tau_{A}$ without any change in $\tau_{B}$ raises the value of the left-hand side in (A1) for $i=B$ above zero. Then, Equation (A1) is violated for $i=B$. By the same reasoning, we get $\left(\partial q_{A}\right) /\left(\partial \tau_{B}\right)>0$. Finally, since $\left(\partial\left(q_{A}+q_{B}\right)\right) /\left(\partial \tau_{i}\right)<0$ and $\left(\partial q_{i^{\prime}}\right) /\left(\partial \tau_{i}\right) \geq 0$, we infer that $\left(\partial q_{i}\right) /\left(\partial \tau_{i}\right)<-\left(\partial q_{i^{\prime}}\right) /\left(\partial \tau_{i}\right)<0$ for each $i, i^{\prime} \in\{A, B\}$ and $i \neq i^{\prime}$.

Proof of Theorem 2. The first order conditions with respect to $q_{A}$ and $q_{B}$ are, respectively, given by

$$
P\left(q_{A}+q_{B}\right)=\kappa F\left(q_{A}+q_{B}\right)+\kappa\left(q_{A}+q_{B}\right) F^{\prime}\left(q_{A}+q_{B}\right)+\delta D^{\prime}\left(\delta q_{i}\right),
$$

for each $i \in\{A, B\}$. Since $D^{\prime}(\cdot)>0$, Equation (A4) for each $i \in\{A, B\}$ implies that the solution of $\left(q_{A}, q_{B}\right)$ should be symmetric. Plug $q_{i}=\left(q_{A}+q_{B}\right) / 2$ into the last term in (A4). Then, $P\left(q_{A}+q_{B}\right)$ strictly decreases in $\left(q_{A}+q_{B}\right)$, while $\left[\kappa F\left(q_{A}+q_{B}\right)+\kappa\left(q_{A}+q_{B}\right) F^{\prime}\left(q_{A}+q_{B}\right)+\delta D^{\prime}\left(\delta\left(q_{A}+q_{B}\right) / 2\right)\right]$ strictly increases. The global first best allocation is uniquely determined by Equation (A4) as long as $\lim _{Q \rightarrow \infty} P(Q) \leq 0$ and $\lim _{Q \rightarrow 0} P(Q)$ is sufficiently large. Note that the unique outcome should be symmetric, i.e., $q_{A}^{*}=q_{B}^{*}$ from the convex environmental damage function.

The constrained planner maximizes the same objective function not by directing $\left(q_{A}, q_{B}\right)$ but by imposing $\left(t_{A}, t_{B}\right)$ subject to firms' first order conditions in (3).

$$
\sum_{i^{\prime}=A, B}\left[P\left(q_{A}+q_{B}\right)-\kappa F\left(q_{A}+q_{B}\right)-\kappa\left(q_{A}+q_{B}\right) F^{\prime}\left(q_{A}+q_{B}\right)-\delta D^{\prime}\left(\delta q_{i^{\prime}}\right)\right] \frac{\partial q_{i^{\prime}}}{\partial t_{i}}=0,
$$

for each $i \in\{A, B\}$. Then, Lemma 1 implies that $\left(\partial q_{i}\right) /\left(\partial t_{i}\right)<-\left(\partial q_{i^{\prime}}\right) /\left(\partial t_{i}\right)<0$ so that $\left(q_{A}^{*}, q_{B}^{*}\right)$ given by (A4) uniquely solves the constrained planner's problem.

Proof of Theorem 3. First, as for non-symmetry cases, suppose that country $A$ implements the cap-and-trade scheme and country $B$ implements the Pigouvian taxation without loss of generality. Then, $q_{A}^{C P}>q_{B}^{C P}$. The details of the proof is provided in the proof of Lemma 4. By comparing (10) and (13)-(15) with the consideration of $\left(\frac{\partial q_{i^{\prime}} / \partial t_{i}}{\partial q_{i} / \partial t_{i}}\right)<0$ from Lemma 1 and $q_{A}^{C P}>q_{B}^{C P}$, we get $P\left(q_{A}^{*}+q_{B}^{*}\right)>P\left(q_{A}^{C C}+q_{B}^{C C}\right)>\max \left\{P\left(q_{A}^{P P}+q_{B}^{P P}\right), P\left(q_{A}^{C P}+q_{B}^{C P}\right), P\left(q_{A}^{P C}+q_{B}^{P C}\right)\right\}$ at each case. It immediately follows that $G S^{*}>G S^{C C}>\max \left\{G S^{P P}, G S^{C P}, G S^{P C}\right\}$.

Now, consider the special case when $F^{\prime}(\cdot)=0$. Plugging $F^{\prime}(\cdot)=0$ into (10), (13) and (14) makes the equations equivalent. As for non-symmetry cases, suppose that country $A$ implements the cap-and-trade scheme and country $B$ implements the Pigouvian taxation without loss of generality. Then, the first order conditions for country $A$ and $B$ are given by (6) and (8) with $F^{\prime}(\cdot)=0$ without superscripts, respectively. Subtracting the latter from the former and reordering yields

$$
P^{\prime}(Q)\left(q_{A}-q_{B}\right)\left[1+\frac{1}{2} \frac{\partial q_{B} / \partial p_{A}}{\partial q_{A} / \partial p_{A}}\right]-\delta\left(D^{\prime}\left(\delta q_{A}\right)-D^{\prime}\left(\delta q_{B}\right)\right)=0 .
$$

From (A6), we infer that $q_{A}^{C P}=q_{B}^{C P}$. Plugging $F^{\prime}(\cdot)=0$ and $q_{A}^{C P}=q_{B}^{C P}$ into (15) yields

$$
2 P\left(q_{A}^{C P}+q_{B}^{C P}\right)=2 \kappa F\left(q_{A}^{C P}+q_{B}^{C P}\right)+\sum_{i=A, B} \delta D^{\prime}\left(\delta q_{i}\right)
$$

which results in the same outcome as in (10), (13), and (14). By the same reasoning, $P C$ case yields the equivalent outcome condition (A7). Hence, we get $P^{P P}=P^{C C}=P^{C P}=P^{P C}=P^{*}$ and $G S^{P P}=G S^{C C}=G S^{C P}=G S^{P C}=G S^{*}$ when $F^{\prime}(\cdot)=0$.

Proof of Theorem 4. We obtain the first order conditions

$$
P^{\prime}(Q)\left(\frac{q_{A}-q_{B}}{2}\right)+P(Q)-\kappa F(Q)-\kappa q_{A} F^{\prime}(Q)-\delta D^{\prime}\left(\delta q_{A}\right)+\left[P^{\prime}(Q)\left(\frac{q_{A}-q_{B}}{2}\right)-\kappa q_{A} F^{\prime}(Q)\right] \frac{\partial q_{B} / \partial p_{A}}{\partial q_{A} / \partial p_{A}}=0,
$$


and

$$
P^{\prime}(Q)\left(\frac{q_{B}-q_{A}}{2}\right)+P(Q)-\kappa F(Q)-\kappa q_{B} F^{\prime}(Q)-\delta D^{\prime}\left(\delta q_{B}\right)=0,
$$

which are equivalent to Equations (6) and (8), respectively, without superscripts. Subtracting (A9) from (A8) and reordering yields

$$
P^{\prime}(Q)\left(q_{A}-q_{B}\right)\left[1+\frac{1}{2} \frac{\partial q_{B} / \partial p_{A}}{\partial q_{A} / \partial p_{A}}\right]-\kappa\left(q_{A}-q_{B}\right) F^{\prime}(Q)-\delta\left(D^{\prime}\left(\delta q_{A}\right)-D^{\prime}\left(\delta q_{B}\right)\right)=\kappa q_{A} F^{\prime}(Q) \frac{\partial q_{B} / \partial p_{A}}{\partial q_{A} / \partial p_{A}} .
$$

If $q_{A}\left(p_{A}^{C P}, t_{B}^{C P}\right) \leq q_{B}\left(t_{B}^{C P}, p_{A}^{C P}\right)$, the left-hand side of (A10) is nonnegative, whereas the right-hand side is strictly negative. It is a contradiction. Thus, we infer that $q_{A}\left(p_{A}^{C P}, t_{B}^{C P}\right)>q_{B}\left(t_{B}^{C P}, p_{A}^{C P}\right)$ and $p_{A}<t_{B}$.

Now, we want to show that $q_{B}\left(t_{B}^{P P}, t_{A}^{P P}\right)>q_{B}\left(t_{B}^{C P}, p_{A}^{C P}\right)$. Suppose on the contrary that $q_{B}\left(t_{B}^{C P}, p_{A}^{C P}\right) \geq q_{B}\left(t_{B}^{P P}, t_{A}^{P P}\right)$. We know that $q_{A}\left(p_{A}^{C P}, t_{B}^{C P}\right)>q_{B}\left(t_{B}^{C P}, p_{A}^{C P}\right) \geq q_{B}\left(t_{B}^{P P}, t_{A}^{P P}\right)=q_{A}\left(t_{A}^{P P}, t_{B}^{P P}\right)$.

Consider an alternative case where country $A$ adopts the cap-and-trade scheme unilaterally and issues $\hat{n}_{A}\left(=\delta q_{A}^{P P}\right)$ number of permits. Denote by $\hat{t}_{B} \in \mathbb{R}_{+}$and $\hat{q}_{B} \in \mathbb{R}_{+}$, respectively, the optimal tax rate and domestic production by country $B$ given that country $A$ issues $\hat{n}_{A}$ number of permits. Then, $\hat{q}_{B}=q_{B}\left(\hat{t}_{B}, p_{A}\left(\hat{n}_{A}, \hat{t}_{B}\right)\right)$ should solve

$$
P^{\prime}\left(q_{A}^{P P}+\hat{q}_{B}\right)\left(\frac{\hat{q}_{B}-q_{A}^{P P}}{2}\right)+P\left(q_{A}^{P P}+\hat{q}_{B}\right)-F\left(q_{A}^{P P}+\hat{q}_{B}\right) \kappa-\kappa \hat{q} F^{\prime}\left(q_{A}^{P P}+\hat{q}_{B}\right)-\delta D^{\prime}\left(\delta \hat{q}_{B}\right)=0 .
$$

Plugging $q_{B}^{P P}=q_{B}\left(t_{B}^{P P}, t_{A}^{P P}\right)$ into (A11) makes the left-hand side negative, which implies that $\hat{q}_{B}<q_{B}^{P P}$.

The total derivative of (8) implies that

$$
\frac{d q_{B}}{d q_{A}}=\frac{-\left[P^{\prime \prime}(Q)\left(q_{B}-q_{A}\right)+P^{\prime}(Q)-2 \kappa F^{\prime}(Q)-\kappa q_{B} F^{\prime \prime}(Q)\right]}{P^{\prime \prime}(Q)\left(q_{B}-q_{A}\right)+3 P^{\prime}(Q)-4 \kappa F^{\prime}(Q)-2 \kappa q_{B} F^{\prime \prime}(Q)-2 \delta^{2} D^{\prime \prime}\left(\delta q_{B}\right)} \leq 0 .
$$

An increase in $n_{A}$ and, hence, $q_{A}$, induces country $B$ to produce less as the best response to it. In light of this, that $q_{A}^{C P}>q_{A}^{P P}$ implies that $q_{B}^{C P} \leq \hat{q}_{B}<q_{B}^{P P}$, which is a contradiction. Therefore, $q_{B}^{C P}<q_{B}^{P P}$.

Lastly, when $q_{B}^{P P}>q_{B}^{C P}$, we obtain the following inequalities:

$$
D S_{A}\left(q_{A}^{P P}, q_{B}^{P P}\right)<D S_{A}\left(q_{A}^{P P}, q_{B}^{C P}\right) \leq D S_{A}\left(q_{A}^{C P}, q_{B}^{C P}\right) .
$$

$q_{B}^{P P}>q_{B}^{C P}$ derives the left-hand side inequality, and the optimality of $q_{A}^{C P} \in \mathbb{R}_{+}$given $q_{B}^{C P}$ provides the right-hand side inequality.

Proof of Theorem 5. (i) We first show the existence and uniqueness of the symmetric solution. Since $P(\cdot)$ is continuous, strictly decreasing, and $\lim _{Q \rightarrow 0} P(Q)>\sum_{i=A, B}\left[\kappa F\left(q_{A}+q_{B}\right)+\kappa q_{i} F^{\prime}\left(q_{A}+\right.\right.$ $\left.\left.q_{B}\right)+\delta D^{\prime}\left(\delta q_{i}\right)\right]>\lim _{Q \rightarrow \infty} P(Q)$, we can well define the unique symmetric pair of $\left(q_{A}^{C C}, q_{B}^{C C}\right)$. Suppose on the contrary that there exists an asymmetric solution $\left(\tilde{q_{A}}, \tilde{q_{B}}\right)$ such that $\tilde{q_{A}} \neq \tilde{q_{B}}$ and $\tilde{q_{A}}+\tilde{q_{B}}=Q^{C C}$. Without loss of generality, let $\tilde{q_{A}}>\tilde{q_{B}}$. The first order condition for each country implies that

$$
\begin{aligned}
P\left(Q^{C C}\right)-\kappa F\left(Q^{C C}\right) & =-P^{\prime}(Q)\left(\frac{\tilde{q_{A}}-\tilde{q_{B}}}{2}\right)+\tilde{q_{A}} \kappa F^{\prime}\left(Q^{C C}\right)+\delta D^{\prime}\left(\delta \tilde{q_{A}}\right) \\
& =-P^{\prime}(Q)\left(\frac{\tilde{q_{B}}-\tilde{q_{A}}}{2}\right)+\tilde{q_{B}} \kappa F^{\prime}\left(Q^{C C}\right)+\delta D^{\prime}\left(\delta \tilde{q_{B}}\right) .
\end{aligned}
$$

Since $\tilde{q_{A}}>\tilde{q_{B}}$, the second equality in Equation (A14) cannot hold. It is a contradiction. Therefore, we conclude that the equilibrium outcome should be symmetric and unique. 
(ii) Next, we want to show $D S_{A}\left(q_{A}^{P C}, q_{B}^{P C}\right)<D S_{A}\left(q_{A}^{C C}, q_{B}^{C C}\right)$. Taking a derivative of (5) with respect to $q_{i^{\prime}}$ yields

$$
\frac{\partial D S_{i}}{\partial q_{i^{\prime}}}=\frac{1}{2} P^{\prime}(Q)\left(\frac{q_{i}-q_{i^{\prime}}}{2}\right)-\kappa q_{i} F^{\prime}(Q)
$$

which implies that, if $q_{i}>q_{i^{\prime}},\left(\partial D S_{i}\right) /\left(\partial q_{i^{\prime}}\right)<0$. Let $\bar{q}=\left(q_{A}^{C P}+q_{B}^{C P}\right) / 2$. Then,

$$
D S_{B}(\bar{q}, \bar{q})<D S_{B}\left(\bar{q}, q_{A}^{P C}\right) \leq D S_{B}\left(q_{B}^{P C}, q_{A}^{P C}\right) .
$$

The first inequality follows from (A15) and the second inequality follows from the optimality of $q_{A}^{P C}$ given $q_{B}^{P C}$. Since $D S_{A}(\bar{q}, \bar{q})=D S_{B}(\bar{q}, \bar{q})$ and

$$
D S_{A}\left(q_{A}^{P C}, q_{B}^{P C}\right)+D S_{B}\left(q_{B}^{P C}, q_{A}^{P C}\right)<D S_{A}(\bar{q}, \bar{q})+D S_{B}(\bar{q}, \bar{q})
$$

we get $D S_{B}\left(q_{B}^{P C}, q_{A}^{P C}\right)>D S_{A}\left(q_{A}^{P C}, q_{B}^{P C}\right)$. The strict inequality in (A17) follows from the convex environmental damage function. Since the square bracket in (15) is negative and given $q_{A}^{C P}>q_{B}^{C P}$ from Lemma 4, $P\left(q_{A}^{C P}+q_{B}^{C P}\right)<P\left(q_{A}^{C C}+q_{B}^{C C}\right)$ so that $G S^{C P}<G S^{C C}$ from (15). Therefore, we get $D S_{A}\left(q_{A}^{P C}, q_{B}^{P C}\right)<\frac{1}{2} G S\left(q_{A}^{C C}, q_{B}^{C C}\right)=D S_{A}\left(q_{A}^{C C}, q_{B}^{C C}\right)$.

\section{References}

1. Working Group III Contribution to the Fifth Assessment Report of the Intergovernmental Panel on Climate Change. Climate Change 2014 Mitigation of Climate Change; IPCC: Geneva, Switzerland, 2014.

2. Krichene, N. World crude oil and natural gas: A demand and supply model. Energy Econ. 2002, 24, 557-576.

3. Hintermann, B. Allowance price drivers in the first phase of the EU ETS. J. Environ. Econ. Manag. 2010, 59, 43-56.

4. Stavins, R.N. Addressing Climate Change with a Comprehensive Us Cap-and-Trade System. Oxf. Rev. Econ. Policy 2008, 24, 298-321.

5. Pigou, A. The Economics of Welfare; Macmillan: London, UK, 1920.

6. Kiyono, K.; Ishikawa, J. Environmental management policy under international carbon leakage. Int. Econ. Rev. 2013, 54, 1057-1083.

7. Sim, S.-G.; Lin, H.-C. Competitive Dominance of Emission Trading over Pigouvian Taxation in a Globalized Economy. Econ. Lett. 2018, 163, 158-161.

8. Helm, C. International Emissions Trading with Endogenous Allowance Choices. J. Public Econ. 2003, 87, 2737-2747.

9. Copeland, B.R.; Taylor M.S. Free Trade and Global Warming: A Trade Theory View of the Kyoto Protocol. J. Environ. Econ. Manag. 2005, 49, 205-234.

10. Carbone, C.J.; Helm, C.; Rutherford, T.T. The Case for International Emission Trade in the Absence of Cooperative Climate Policy. J. Environ. Econ. Manag. 2009, 68, 266-280.

11. Fanschland, C.M.R.; Edenhofer, O. To Link or Not to Link: Benefits and Disadvantages of Linking Cap-and-trade Systems. Clim. Policy 2009, 9, 358-372.

12. Ranson, M.; Robert N.S. Linkage of Greenhouse Gas Emissions Trading Systems: Learning from Experience. Clim. Policy 2015, 16, 284-300.

13. Doda, B.; Taschini, L. Carbon Dating: When is it beneficial to link ETSs? J. Assoc. Environ. Resour. Econ. 2017, 4, 701-730.

14. Sartzetakis, E. Raising Rival's Costs Strategies via Emission Permits Markets. Rev. Ind. Organ. 1997, 12, 751-765.

15. Weitzman, M. Price vs. Quantities. Rev. Econ. Stud. 1974, 41, 477-491.

16. Goulder, L.; Schein, A. Carbon Taxes versus Cap and Trade: A Critical Review. Clim. Chang. Econ. 2013, 4, $1-28$.

17. Fowlie, M. Incomplete Environmental Regulation, Imperfect Competition, and Emissions Leakage. Am. Econ. J. Econ. Policy 2009, 1, 72-112. 
18. Baylis, K.; Fullerton, D.; Karney, D. Negative Leakage. J. Assoc. Environ. Resour. Econ. 2014, 1, 51-73.

19. Hoel, M. The Triple Inefficiency of Uncoordinated Environmental Policies. Scand. J. Econ. 2005, 107, 157-173.

20. Liski, M.; Tahvonen, O. Can carbon tax eat OPEC's rents? J. Environ. Econ. Manag. 2004, 47, 1-12.

21. Strand, J. Importer and Producer Petroleum Taxation: A Geo-Political Model; IMF Working Papers; IMF: Washington, DC, USA, 2008.

22. Yanase, A. Dynamic Games of Environmental Policy in a Global Economy: Taxes versus Quotas. Rev. Int. Econ. 2007, 15, 592-611.

23. Boom, J.-T.; Dijkstra, B.R. Permit Trading and Credit Trading: A Comparison of Cap-Based and Rate-Based Emissions Trading under Perfect and Imperfect Competition. Environ. Resour. Econ. 2009,44, 107-136.

24. Dertwinkel-Kalt, M.; Haucap, J.; Wey, C. Raising rivals' costs through buyer power. Econ. Lett. 2015, 126, 181-184.

25. Biglaiser, G.; Horowitz, J.; Quiggin, J. Dynamic Pollution Regulation. J. Regul. Econ. 1995, 8, $33-44$.

26. Fischer, C. Emission Pricing, Spillovers, and Public Investment in Environmentally Friendly Technologies. Energy Econ. 2008, 30, 487-502.

27. Weber, T.; Neuhoff, K. Carbon Markets and Technological Innovation. J. Environ. Econ. Manag. 2010, 60, 115-132.

28. Kim, S.-L.; Lee, S.-H. Eco-Technology Licensing under Emission Tax: Royalty vs. Fixed-Fee. Korea Econ. Rev. 2014, 30, 273-300.

29. D'Amato, A.; Dijkstra, B. Technology Choice and Environmental Regulation under Asymmetric Information. Resour. Energy Econ. 2015, 41, 224-247.

30. Sim, S.-G.; Hong, S. Technology Spillover and Environmental Policy Instruments: Price Control Versus Quantity Control; SSRN Working Papers; SSRN: Amsterdam, The Netherlands, 2017.

31. Holtsmark, B.; Sommervoll, D.E. International Emissions Trading: Good or Bad? Econ. Lett. 2012, 117, 362-364.

(C) 2018 by the authors. Licensee MDPI, Basel, Switzerland. This article is an open access article distributed under the terms and conditions of the Creative Commons Attribution (CC BY) license (http:/ / creativecommons.org/licenses/by/4.0/). 